\title{
Is Performance Improvement possible by generating high levels of Focus in Individuals to create Flow?
}

\author{
Eddie John Paul Fisher and Yorkys Santana Gonzalez \\ Faculty of Social Sciences, Universidad de Oriente, Santiago de Cuba, Cuba
}

Eddie Fisher (Corresponding author)

8 Kendal, Swindon, Wiltshire, SN5 8HW, United Kingdom

Tel: 44-179-349-0423 E-mail: eddie.fisher9@btinternet.com

Received: March 21, 2016 Accepted: April 7, 2016

doi:10.5296/ber.v6i1.9195 URL: http://dx.doi.org/10.5296/ber.v6i1.9195

\begin{abstract}
The ability to improve performance levels at work through the development of flow has the potential to become a new management skill for managers. The outcome of this research suggests that managers can achieve higher performance levels in each of their team members. It is a necessary condition that they, for example, lead them by example, allow people to act within their abilities, show them how to mask distractions and create mental and emotional fitness within people's minds. It appears that more than one component of flow is necessary to develop what is generally referred to as a state of flow. The outcome of this research suggests that the contribution flow makes to performance improvement can be measured through appropriate Key Performance Indicators (KPIs).
\end{abstract}

Keywords: Flow, Focus, Concentration, Attention, Performance Improvements

\section{Introduction}

\subsection{Introduction}

It appears that in today's fast moving business environment, fewer people are able to focus their attention at work on what is really important to conduct their business or fulfil their duties. They are no longer able to apply the so-called Pareto-principle of 80/20 (Vilfredo Pareto, 1906) by focusing their minds on the $20 \%$ of effort that provides $80 \%$ of what is important to be done. Senior Managers are setting much higher productivity levels. Managers are now expected to deliver more with fewer people in less time and to increasing levels of quality. People live in a world that is full of technological advances such as smart phones and content and applications. 
One downside of this is that there are many distractions that often prevent people from focusing on what is important or relevant to achieve the goals they have set themselves.

Focusing on the important things can be improved by identifying the strengths of individuals and then focus their attention on improving these. This is equally relevant at work, leisure and at home (Hood et al., 2014). Many people seem to understand what the concepts of focus and attention stand for but it is considered less clear what the positive potential consequences are, when applied, to how people perform at work. Managers, for example, who invest more time to improve their own focus, attention and concentration skills, are also more likely to improve those of staff under their supervision. According to Sasson (2012) the power of concentrating is essential for success in every area of life, at work, at home, at school and in college, in sports and in business, for achieving goals and completing tasks, and for self-improvement and meditation.

It appears that some work environments, such as Court Rooms, require more than just high levels of focus and attention (one of the researchers observed court proceedings over a period of six months to collect empirical evidence). Levels of concentrated focus are very high as both the judges and the magistrates need to put their undivided attention towards what is being said by all parties. This is essential for making the correct and justified decisions as far as judgements are concerned. Judges point out to the Defence to only focus on what is relevant and important to their particular case. Judges and Magistrates appear to be in a state of 'Flow' (Section 1.1.2). What is good enough for the Court Room, appears to be good enough for work situations. This research has adopted the following interpretations of what is meant by focus, concentration and attention:

Pillsbury (1908) defines the concept of focus and attention as 'The manifestations of the state which we commonly call attention are protean. No part of the individual is untouched by them. They extend to every part of the physical organism. All are amongst the most profound facts of mind. So numerous and varied are the ramifications of attention that we find it defined by competent authorities as a state of muscular contraction and adaptation, as a pure mental activity, as an emotion or feeling, and as a change in the clearness of ideas'. In contrast, James $(1890 ; 1950)$ considers that attention is the taking possession, by the mind, in clear and vivid form, of one out of what seem simultaneously possible objects or trains of thought.

More definitions of Focus (accessed 3 August 2014, source Internet):

a.) 'The centre of interest or activity. An act of concentrating interest or activity on something.'

b.) 'A centre of interest or activity. Close or narrow attention or concentration. A condition in which something can be clearly apprehended or perceived.'

c.) 'Filter-selective attention is the ability to focus only on what really matters, blocking out the chaos'

d.) 'Control-being in charge of the situation and being able to override automatic responses in favour of a more considered response to achieve higher goals' 
Improving productivity levels in work environments has become a major concern for employers as well as management. The purpose and goals of this research are to investigate and report how effective applications of focus and concentration can improve business performance. The outcome of this research will deliver practical suggestions how focus and concentration levels can be improved and what applications are needed to achieve the desired results.

A literature review is presented next, followed by the main research questions/hypotheses for this research and the knowledge gap identified from the literature review. This forms the theoretical framework of this research and is followed by a presentation of the outputs from face to face interviews with a large group of students of psychology/social psychology from the Universidad de Oriente in Santiago de Cuba. The research methodology is presented next. This is followed by the research results and the discussion of what the research found. The conclusions are presented next. This includes this research's limitations, suggestions for future research and whether the main research questions have been answered.

\subsection{Literature Review}

\subsubsection{Focus and Concentration/Attention}

It appears that the subject of focus and concentration/attention has been of interest for quite some time and was first summarised by Ribot (1890). Attention guides human behaviour and this includes someone's own behaviour. Herman Von Helmholtz, a German psychologist (1821 to 1894) argued that the relation between attention and perception was one of the first topics to be studied by experimental psychology. Attention is essential for visual perception. For example, using printed letters, he showed that the eyes could be directed to other parts of a letter even though they were fixed on a particular point of the letter (perception). Much later, Mackworth (1970) defines the concept of attention 'as a mental faculty that selects one or more external stimuli or internal mental events or traces' (page 13). Mackworth considers that the concept of attention returned in the 1970s in psychological and physiological research.

At the simplest level, attention involves focusing on one stimulus only while ignoring any other stimulus. Some stimuli are monotonous such as the voice of a speaker or a plethora of slides. This monotony can be changed, for example, by the addition of jokes, some provocative and innovative pictures or by simply creating arousal in the audience by using emotional remarks. It is then possible to maintain the audience's level of interest and attention. In addition, gestures, unusual body language and loudness/intonation of voice can also aid elongating the attention span of an audience.

Magill (2011) reports that the concept of attention has been of interest since human behaviours have been investigated. For example, Sir William Hamilton (1859) conducted some research in the United Kingdom that covered attention. William Wundt, generally acknowledged as the 'father' of experimental psychology, investigated attention at the University of Leipzig in Germany. In 1890, William James in the United States defined attention as the focalisation and concentration of consciousness. Magill defines attention as 'In human performance, characteristics associated with consciousness, awareness and cognitive effort as they relate to 
the performance of skills with particular reference to the limitations with these characteristics on the simultaneous performance of multiple skills and the detection of relevant information in the performance environment' (page 441). Magill defines attentional focus as 'The directing of attention to specific characteristics in a performance environment, or to action preparation activities' (page 441). Magill raises an interesting and relevant question about human performance and learning: Why is it easy for human beings to do more than one activity at a time in one situation, but difficult to do these same things simultaneously in another situation? Another aspect of attention happens when people need to make visual selections and attend to specific happenings within this environment before people proceed with the execution of actions. For example, people look at the key hole in a door first before attempting to put the key in. Similarly, when people drive a car, they need to visually select information to get them safely to their destination. The same applies to sports. For example, in football a player needs to evaluate the visual situational information before passing a ball. These types of so-called motor skill performance situations are part of the concept of attention.

Johnson and Proctor (2004) argue that it is necessary to select or ignore some things if people wish to produce coherent behaviour in the face of competing and distracting sources of stimulation. Human beings cannot attend to everything that is going on around them. They would be constantly distracted by things that are not important, for example, to their goals or objectives. It is for this reason that human beings need to focus their attention on only what is relevant to them and only act on what is relevant and essential. Johnson and Proctor quote James (1890) who purports that concentration and focus are the essence of attention. The attention demands placed on people become evident when people need to do more than one task at a time. This is particularly relevant at work. Most people at work need to perform multiple tasks simultaneously. Although information comes in from multiple sources, people must decide which of the information is relevant to current task demands. Focused attention is needed to ensure that people act only on what is relevant and ignore all else. Most real-world tasks have both divided and focused attention components.

According to the following authors and life coaching professionals, the focus and concentration levels of people at work can be enhanced in a number of ways:

1. Stay Connected: 'Find things to do that make you feel happy with a sense of belonging', suggests hypnotherapist and author Georgia Foster. 'Connection to people is very important, as well as finding something that keeps the brain stimulated with lots of positive chemicals such as endorphins.'

2. Learn new Skills: 'Make it your business to learn new skills and take up hobbies but do not just think of them as your little hobbies-allow yourself to be passionate about them', advises life coach Annie Kaszina. 'Write a book, take up painting or complete a University degree. There are plenty of things you can do where age is no barrier.'

3. Exercise Body and Mind: 'Regular physical exercise is important', says GP Dr Michael Spira. 'But studies also show that activities that stimulate the brain are equally important: reading books, going to lectures, taking part in quizzes, crosswords, other puzzle games, bridge, chess, writing and charity work. Eating a healthy diet with plenty 
of fresh fruit and vegetables can also help keep the mind sharp.'

4. Set some Goals: 'Set some challenging goals that will help the brain to stretch itself in healthy ways', adds Georgia Foster who is offering a new online course on self-esteem. 'Start a new course or join a new group of people who will help to stimulate more confidence and a sense of belonging.'

Beilock (2010) conducted some extensive research to provide new insights into what influences poor performance under pressure in various situations such as at work and in sport, and what people such as managers can do to prevent failure in their own endeavours. Beilock considers that as people get better and better at performing skills such as operating a mobile phone, people's conscious memory for how people do it gets worse and worse. People become more expert and their procedural memory grows but they may not be able to communicate their understanding or help others learn that skill. Relating this to work, business managers need to become much better estimators as far as the skills and abilities of their team members are concerned. It appears that consulting someone less experienced provides benefits for more experienced people such as managers. For example, before delegating the management of a new project, managers should consult with team members to get an idea of the issues they think they might have to manage in this project and what help and support they might need to resolve these. This approach will facilitate to synchronise team members and the manager. The results are more accurate work, improved estimates for their clients and happier customers overall.

Davidson (2011) reports that attention blindness- a basic feature of the human brain-is caused when people focus intensely on one task or thing, and by doing so, they miss just about everything else. For example, in one associated experiment, participants were asked to count the number of ball tosses between a certain group of people (those in white shirts against others in black shirts). Half way through the exercise, a person dressed up like a gorilla appeared in front of the camera, thumped the chest and then walked away. When the participants were asked how many tosses took place, different results were presented. When asked 'Who saw the gorilla?', only a very small number of people confirmed that they saw the gorilla. When the tape was replayed, everyone saw the gorilla. People were deceived by their own minds. It appears that those who did see the gorilla were not paying attention to counting the number of tosses between players with white shirts. People think they see the whole world but in reality they only see a very particular part of it. Learning from the experiment, Davidson suggests that here is an opportunity to work together, by synchronising what people see selectively. The advantage of this approach is that the shortcomings of individuals are filled in by what others have not missed. In the case of the experiment, this means that people can pool their insights and together see the whole picture. The benefits of this, for example, in the business worlds, are enormous. The world is a chaos without focus and attention.

Focus allows people to concentrate on what is most useful and important. In contrast, focus means selection and this can leave people with so-called 'blind spots'. Davidson quotes the work of Simons and Chabris (1999) who came up with a convincing way to illustrate the cognitive principle of selective attention that had been developed and identified in the 1970s but was not accepted as believable. Davidson argues that attention blindness is a key to 
everything people do, both at home and at work.

Schmidt and Wrisberg (2000) define 'focus of attention' by quoting Nideffer (1995) as 'The act of directing attention to information sources or the object of an individual's attention. A person can direct his or her focus to external or internal sources of information and can narrow or broaden the focus to include few or many stimuli' (Fig. 2):

- External Focus: the act of attending to sources of information in the environment

- Internal Focus: the act of attending to internal information such as thoughts, feelings or kinaesthetic cues

- Narrow Focus: the act of attending to a narrow range of information at one time

- Broad Focus: the act of attending to a wide range of information at one time

Nideffer suggests that it is important for practitioners to be able to assist learners in directing their attention/focus to the most relevant sources of task information at all times. Nideffer reports that there are four dimensions of attention individuals have the capability of controlling (Fig. 2). An external focus is used when individuals attend the cues or information in the environment. An internal focus is employed when people attend to their own thoughts and feelings. The second dimension concerns the width of attentional focus- a narrow focus is one that encompasses a small amount of information whereas a broad focus is one that is sensitive to a large number of cues at the same time. Turning attention to real life situations, particularly at work, practitioners can coach/guide individuals to direct their attention to any of a number of internal or external sources for information. The biggest challenge for practitioners is to determine the optimal focus for each task. Relating this to work environments, managers need to select the right combination of narrow/broad and internal/external focus to produce better learning. Mangers, for example, can thus encourage the development of attention control in individuals according to the situation.

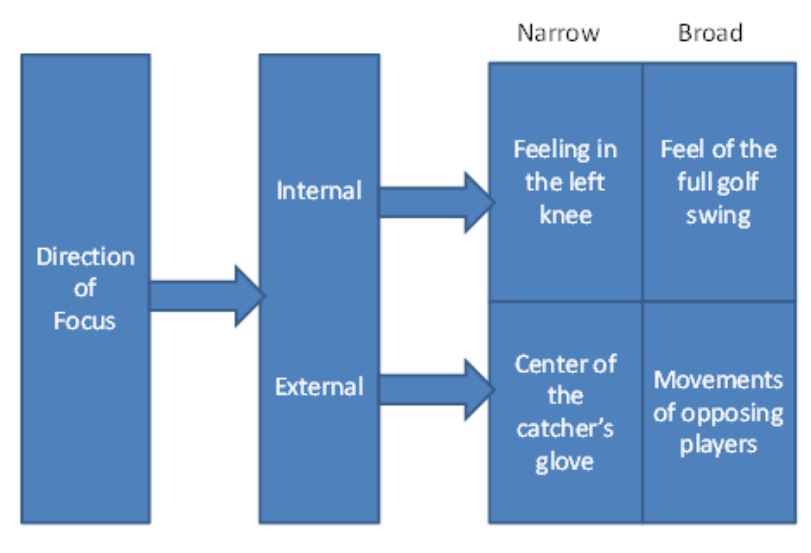

Conceptualisation of Attention (Nideffer, 1995)

Fig. 1. Conceptualisation of Attention, adopted from Nideffer (1995) 


\section{Al Macrothink}

Business and Economic Research

ISSN 2162-4860

2016, Vol. 6, No. 1

Brown and Fenske (2010) argue that those people who are successful in life, appear to be engaging their neuro-circuitry in such a way that they can achieve their potential and goals. Resilience and motivation are critical abilities associated with success. Successful people focus their attention on the most important details, ignoring things that do not actually make a contribution to be successful. Incorporating relevant details into the broad focus stimulates and encourages the brain to become more innovative, flexible and creative. Brown and Fenske suggest that people's goal laser and effort accelerator 'rely on Focus to stay locked on your goals and to create the synergy needed to keep moving forward' (page 84). They quote James (1890) who defines focus as taking possession of the mind, in clear and vivid form, of one out of what seem several simultaneous possible objects or trains of thought. Conscious focalisation and concentration are the essence of focus. Brown and Fenske propose a more simplified definition of focus. As focus involves attention and concentration, focus is the mental energy required to gather significant details and tune out unnecessary distractions. Levels of focus and attention can be improved through regular practice. Regular stimulation of these powers of attention and concentration can change the physical make-up of the brain itself. This in turn can lead to improved levels of focus. It is the ability to concentrate and maintain a narrow focus that enables people to triumph and succeed. It is like putting 'blinkers' on the mind so the brain focuses on what is important.

Brown and Fenske suggest that it is possible for people to get back on the right track following a brain lapse. Repetition plays an important role in developing effective approaches to improve levels of focus and attention. Recurring pieces of information are stored (part of the brain). This frees up room for focusing on the important aspects that still require conscious thought and control. 'Of course it's obvious that practice leads to skill improvement, but a large part of that improvement boils down to the fact that attention is a finite resource if your brain is busy fumbling around trying to remember how to do something, too many resources get dedicated to the route aspects of the job' (page 98; note that learning is memorisation technique based on repetition). It is imperative that managers encourage their team members to relax their attention from time to time whilst being fully immersed in what they are doing. This was described by Csikzentmihalyi (1991) as the state of flow, and it appears to be one of the keys to certainty (see Section 1.2 (Csikzentmihalyi, 1997).

Performance increases with emotional stimulation. Not only is there an optimal emotional state for each situation, there is also an optimal emotional volume. This notion has evolved from what is generally referred to as the Yerkes-Dodson (1908) law who first recognised that there is a relationship between the intensity of stimulation and task performance (Fig. 3). 


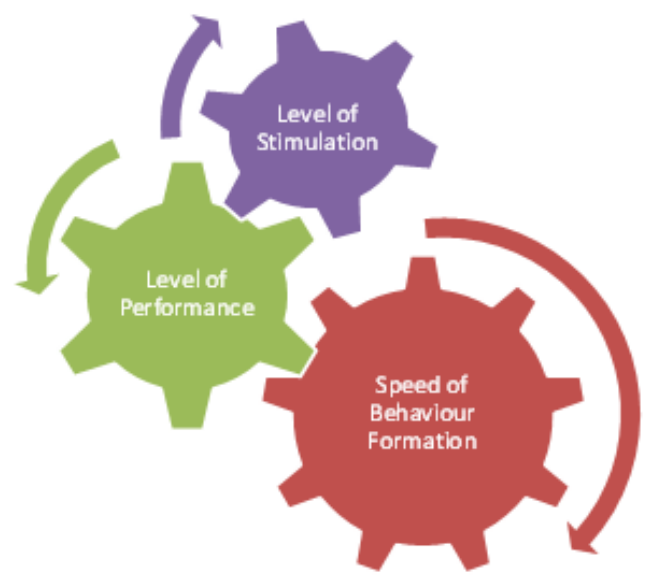

Fig. 3. Effect of Emotional Arousal on Performance (adopted from Yerkes-Dodson, 1908)

According to Kelsey (2014), unless human beings have motivation or are motivated, they will not go very far. This is particularly true if motivation is not sustained. Kelsey quotes Gorman (2007) who claims that 'If you are doing something, pursuing something or achieving something, you are somehow motivated to do it, pursue it or achieve it'. 'Motivation ignites, energizes, determines, directs and explains our behaviour'. Gorman considers that negative self-beliefs are the enemies of motivation. It is important that people understand that negative self-beliefs are part of the journey to higher levels of motivation. Negative self-beliefs kill positive motivation. It helps to set achievable goals to focus on motivation and on the things that can be achieved and obtained. Based on the considerations of Cairo (1998) and other authors, Kelsey suggests that people should engage the following key steps to set their goals:

1. Goals should excite people

2. Goals should reflect people's values

3. Goals should be specific and challenging

4. People should take time to visualize their goals

5. Write down goals

6. People should reward themselves

7. Focus on (and find) their talents

Cranfield et al. (2013) argue that a lack of focus is still one of the biggest factors that prevents people from achieving their goals in life or being successful. It is the combination of life experiences and focus/concentration that make things happen. This has been earned by making lots of mistakes as well as by focusing on doing some things extremely well. It is possible to programme and re-programme people's focus and concentration levels. It appears that this is dependent on people's habits. Successful people have successful habits. Cranfield et al. define a habit as something people do so many times that it becomes easy. It is a behaviour that people keep on repeating. Continuing to develop any new behaviour, this will ultimately become an 
automatic behaviour. It is these habits that will determine how people, for example, will perform at work through their levels of focus and concentration.

\subsubsection{Flow}

According to Csikszentmihalyi (1997), it takes a lot of effort for an adult professional to take on board the knowledge and skills needed for them to perform their job well. This includes the necessary mental operations to comply with expected high performance levels. When people learn to concentrate, they acquire control over psychic energy. All thinking depends on this. People's different contents of experience are often not synchronised. For example, part of their attention may be focused on some work they do for the manager whilst another part of their attention is focused on a personal problem at home. People's attention can thus be pulled in different directions.

Csikszentmihalyi suggests that there are other occasions when people cannot afford to have their attention levels divided. For example, going down a ski slope at high speed requires total focus and attention to avoid a serious accident. In situations like these it appears that people experience something Csikszentmihalyi refers to as flow experience. Many people have used to describe this sense of free-flowing action as one of the best things they have experienced in their lives. Athletes refer to this experience as 'being in the zone'. Some artists and musicians call it an 'aesthetic rapture'. It appears that flow occurs when a clear set of goals requires appropriate responses. This happens, for example, in games such as chess or tennis. The player lives in a self-contained world where everything is just black and white. 'In contrast to normal life, flow activities allow a person to focus on goals that are clear and compatible' (page 30).

Flow happens when challenges can just be managed by engaging one's skills to overcome the challenge. Optimal experiences occur when it is possible for people to act within their abilities and the available opportunities to do so. Fig. 4 illustrates the fine balance between challenges and skills, and the situational experiences people face in their daily lives such as anxiety, control and boredom.

When challenges and skills levels are high, flow occurs. In contrast, when challenges and skills are low, apathy occurs. Relating this to work, it means that mangers, for example, need to improve people's skills if they wish people to move from 'Arousal' to 'Flow' for those who already have some skills. Equally, if people already have high skill levels, and they are in the 'Relaxation' category, managers need to provide them with more challenges to lift them up into the desired 'Flow' category. The benefits of the flow experience are that it acts as a catalyst for learning. It can help managers to develop new levels of challenges and skills for their team members. This can be achieved by constantly growing people while they enjoy what they are doing. 


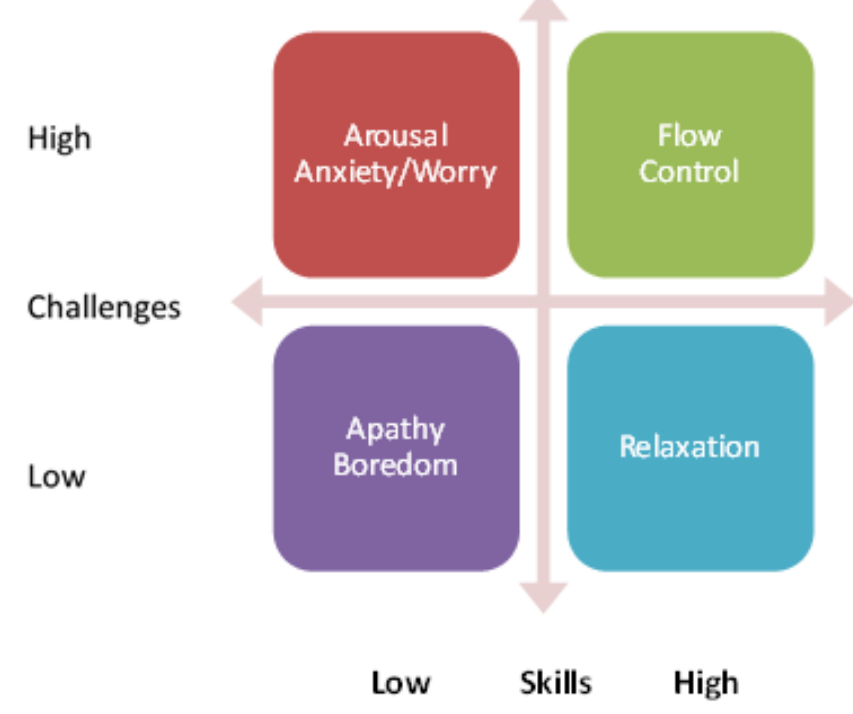

Fig. 4. Balance between Challenges and Skills to achieve Flow (Csikszentmihalyi, 1997)

It is possible to enhance people's focus and concentration levels by encouraging them to set their own goals. When applied correctly, it is thus possible, for example, for managers to lead their team members to new levels of peak performance and productivity. Focus and concentration can become the catalysts for achieving personal goals. Goleman (1998) refers to this unique state of mind as an ecstatic state or flow. Those who have experienced this state of flow, describe it as being devoid of one-self. Flow drives people to do their best work, irrespective of what work they do. Another way to describe flow is not being aware of distractions that surround people and doing things without thinking about them. Goleman concludes that during flow, the brain appears efficient and precise in its pattern of firing.

According to Tsaousides (2015), attention is a complex cognitive process which involves several discreet neural and whose primary function is twofold: to allow human beings to select what incoming information they should process and to choose how to act on that information. Information, in this case, includes input from the senses, the mental representations (thoughts, ideas and memories) and people's current behaviours. For example, people's attention allows a driver approaching an intersection to notice the changing traffic light or prompts the driver to actively look for signs or traffic lights to determine how to proceed. Attention is a critical factor in goal achievement. It facilitates of task completion. Tsaousides suggests that deficits in attention lead to reduced and of attention, three types of attention are critical in managing the modern work environment: focus, concentration and multi-tasking:

1. Focus is the product of selective attention. Selective attention is the ability to concentrate on a target stimulus and ignore non-target stimuli. Selective attention encompasses the notion of freedom from distractibility. Focus allows people to have a conversation with a client on the phone, for example, while ignoring the background chatter in the office, or what allows people to deliver a luncheon presentation to their team, despite crunchy noise of potato crisps being eaten. The most effective way to increase their focus is to reduce distractions, either by removing them (such as close the 
door or have only one application open on the computer) or by masking them (playing background music or white noise, to mask distracting sounds)

2. Concentration is the product of sustained attention. It is the ability to maintain attention during a continuous or repetitive task for prolonged periods. Concentration is required when completing a task that requires conscious processing, for example, is not automatic-during long uninterrupted time intervals. Reading a contract or listening to a monotonous lecturer, for example, are tasks that require high levels of concentration. Increasing concentration can be achieved through a variety of mindfulness exercises and through active engagement with the task such as taking notes during a tedious lecture

3. Multitasking is the product of alternating attention. Alternating attention is the ability to shift one's focus. It requires disengaging attention from one task and engaging in another. Multitasking is often erroneously construed as the ability to process multiple stimuli or perform multiple tasks at once, referred to as divided attention

Tsaousides reports that more recent research has shown that divided attention is actually a form of alternating attention where one's focus shifts rapidly from task to task in a way that appears seamless. This type of approach to task reduces and increases fatigue. Multitasking may be inevitable in the modern work environment but it is ineffective. The best approach to maintain a high level of performance on two tasks is to completely disengage from Task 1 such as stop working on the spreadsheet, engage in Task 2 such as answer the phone, disengage from Task 2 such as hang up the phone and return to Task 1 by going back to the spreadsheet.

\subsection{Main Research Questions}

The main research questions for this research are:

1. What is known about the concepts of focus, concentration and flow? What are their relationships?

2. What does an effective manager look like who can raise the focus and concentration levels within their team members?

3. How can the outcome from this research be applied practically at work?

4. Does a shortfall exist between the level of performance people at work could achieve in today's working environments and the level they are currently achieving if their focus and concentration levels could be raised?

\section{Research Methodology}

\subsection{Method}

The researchers applied a constructivist interpretivist research approach within a phenomenological research paradigm. This qualitative research approach was considered most appropriate as the researchers wanted to get close to the subject matter under investigation within what they consider to be a socially constructed world. Table 1 is a summary of the 
questions asked during the face to face meetings with the research participants. All answers were recorded in writing or electronically where possible. Students provided their full approval. 30 undergraduate students from the Universidad de Oriente in Santiago de Cuba, Cuba were interviewed over a three months' period in the last quarter of 2015. Of these 25 were female and 5 were male. Their age ranged from 19 to 22 years. All were undergraduate students from the Faculty of Social Sciences in their third (17) or final year (13). All students had extensive experience in the areas of psychology/social psychology and their own work experiences. They provided valuable insights for this research.

Table 2. Research Questionnaire for the Face to Face Interviews

\begin{tabular}{|rl|}
\hline 1. & What is your definition of 'focus' and 'concentration'? \\
\hline 2. & Describe different focus/concentration levels and explain why this is so. \\
\hline 3. & What factors influence the focus/concentration levels such as food, drink and cigarettes), and why? \\
\hline 4. & How do you increase your levels of focus and concentration? What are the results? Can you \\
& measure these? If yes, how? \\
\hline 5. & Do high levels of focus/concentration necessarily lead to high performance levels at work? \\
\hline 6. & Higher levels of intelligence lead to higher levels of focus/concentration. Discuss. \\
\hline
\end{tabular}

\subsection{Data Collection and Interpretation}

The researchers considered two methods to collect relevant research data to answer the main research questions from Section 1.3: a review of the literature (Section 1.2) and face to face interviews (Section 3), within the context of a phenomenological research paradigm and an associated constructivist interpretivist research approach. The outcome of each research method such as literature review and face to face interviews increased the contributions made to answer the research questions from Section 1.3. The findings from each of the research methods such as literature review and face to face interviews were based on an evidential analysis and interpretation of all collected research data. This was enriched by the contemporary view contributions from the interviewees and allowed for a balanced view to be presented. All interviews were conducted in a consistent and methodical manner. The researchers probed further from time to time when interviewees were not forthcoming with sufficient supportive evidence. The result was a high level of data reliability and validity. Table 3 is a summary of the application and ranking of the examined focus, concentration and attention skills.

\section{Results}

\subsection{Face to Face Interviews}

What is your definition of 'focus' and 'concentration? 'Both are closely related. Focus is about tranquillity. It disciplines us to know how to listen actively, for example. Focus is knowing that you want to achieve something. Focus impact concentration-not the other way round (Celia, Dahlia).' 'Concentration is a cognitive state people reach or arrive at that allows for the development of some superior processes that, ultimately, guide the behaviour that follows. For example, concentrating on what the teacher says in the classroom to understand the content as intended (Debie, Margie).' 'Focus is about directing the resources needed to 
complete a certain task satisfactorily. It's about avoiding any distraction that disturbs us to concentrate on what is important to achieve our goal (Sergio, Deborah).'

'I suggest that concentration is holistic, looking at something in its entirety. Focusing is limited to one element at a time of the whole concentration (Claudia).' 'There is a relationship between the two. We need to know the reason for a task first (so we can focus). We then should put all our resources towards achieving the goal of concentration (Maria, Dalila).' 'Focus is more based on knowledge and experience. Concentration is more a process that directs resource to the physical or mental activity we want to complete. Focus then precedes concentration (Yoima).'

Describe different focus/concentration levels and explain why this is so. 'Every person is different. Some people have high levels of energy and it appears that these also have high levels of focus. Some people also find it easier to focus than others (Aliuska).' 'It sometimes depends on the task in hand. If we like something particularly well, then our focus levels will naturally be much higher (Yelitza, Talia).' When I am disassociated from the task, when I do not concentrate, and when I am not motivated to do something, then my focus level is very low.

It all depends on my state of mind at the time (Madeleine).' 'It depends on the activity level. The higher and more complex it is, the higher the attention level needs to be, and therefore higher levels of focus and concentration (Eslayne, Camilo).' 'Our focus and attention levels are in our favour when we concentrate on a certain task. The opposite is true when we get distracted so we disassociate with the task we are trying to carry out (Betsy, Mailin, Alexis, Yoima).'

What factors influence the levels of focus and concentration, for example, food, drink and cigarettes, and why? 'Social, biological and the personal characteristics of people can influence both focus and concentration levels. For example, students who attend classes at University after a heavy night are unlikely to be able to focus their attention on what is being taught. In contrast, those who have complete silence and who drink lots of water, are more likely to focus and concentrate on the task in hand (Celia, Leticia, Lorianne, Roxana).' 'These factors are influential in that they form part of an individual's life. As such, they appear to mobilise human behaviour. Some of the associated mental processes are our state of mind, our physical condition and the functioning of our mental processes, to name a few (Lleana, Eslayne, Daniel, Belize).' 'Attention and perception are the primary factors that influence focus and concentration levels. Food also plays an important nutritional factor as energy levels affect the levels of focus and concentration and their duration (Patricia, Camilo, Daniela, Angel).' Emotions, or how we feel, can also influence our ability to focus and concentrate on what is important. Emotions can create conflicts of interests and this can lead to conflicts of focus. The mind may become confused what is important and what is not (Mailin, Alexis, Yoima).' ‘

How do you increase your levels of focus and concentration? What are the results? Can you measure these? If yes, how? 'By balancing the things that are important to me in all aspects. Having an adequate amount of sleep, for example, and understanding what the things are that keep me motivated to do the right things well. Taking a more holistic view on the topic that requires my focus and attention also helps. Getting rid of psychological stimuli that disturb 
me to focus, such as concerns or personal problems (Celia, Angela, Aliuska).' 'Being in a place where there are no interruptions. And paying more attention to the things that are important (Dahlia, Sergio).' 'Developing some personal strategies to achieve the things that are important to me helps to concentrate on the tasks I need to carry out (Eslayne).'

'Postponing the things that are not so important and get in the way helps to focus our attention on what is really important (Daniel, Maria, MSM).'

Do high levels of focus/concentration necessarily lead to high performance levels at work? 'Absolutely yes. Higher levels of knowledge develop necessarily when we focus our attention. This knowledge then leads to higher levels of motivation which in turn increases performance levels. Concentration is related to attention, memory and language, for example. If these are in a good condition and in the right frame of mind for the task in hand, then higher levels of productivity and efficiency can be achieved (Celia, Aliuska, Madeleine, Dalila, Claudia).' 'Yes, high levels of focus and concentration reduce levels of distractions so better result can be achieved (Eslayne).' If we understand what we are going to make, why and for what valid reason, then it is more likely that we will direct all our resources towards achieving that task. We are, therefore, more likely to be successful in our endeavours (Mailin, Yoima).' 'Not always. High levels of focus and concentration can sometimes cause a blockage that will affect the desired outcome because we are simply focusing our attention too much on the task (s) in hand. It is like 'not seeing the wood for the trees' (Debie).'

Higher levels of intelligence lead to higher levels of focus/concentration- Discuss. 'I do not agree with this statement. For example, a student with a good concentration level can learn things better than a more intelligent student with an inadequate level of concentration. It is the level of attention that is paramount and not the level of intelligence (Celia, Debie, Aliuska, Margie).' 'The capacity 'intelligence' not necessarily impacts the achievement of high concentration levels and focus (Patricia, Eslayne, Maria).' 'Being intelligent does not mean that you are necessarily also good at concentrating well on things. It probably just indicates that you possess the right mechanisms to, for example, solve certain problems effectively (Camilo, Angel).' There are some very intelligent people in the world who are not able to exploit their capacity to the full because they lack concentration (Belize, Mailin).

Table 3. Application and Ranking of the examined Focus, Concentration and Attention Skill Sets

\begin{tabular}{|l|l|l|}
\hline Skills Set & Application & Ranking \\
\hline $\begin{array}{l}\text { Focus, Concentration, } \\
\text { Attention and Flow }\end{array}$ & $\begin{array}{l}\text { Developing team members' attention levels will } \\
\text { guide their behavior at work, for example, in a } \\
\text { positive way } \\
\text { Influencing others to focus only on what is relevant } \\
\text { will save time and effort and reduce costs } \\
\text { Encouraging staff at work to exercise body and mind }\end{array}$ & $\begin{array}{l}\text { Identified by all parties as being } \\
\text { important * }\end{array}$ \\
& $\begin{array}{l}\text { Identified by all parties as being } \\
\text { important * }\end{array}$ \\
\hline
\end{tabular}




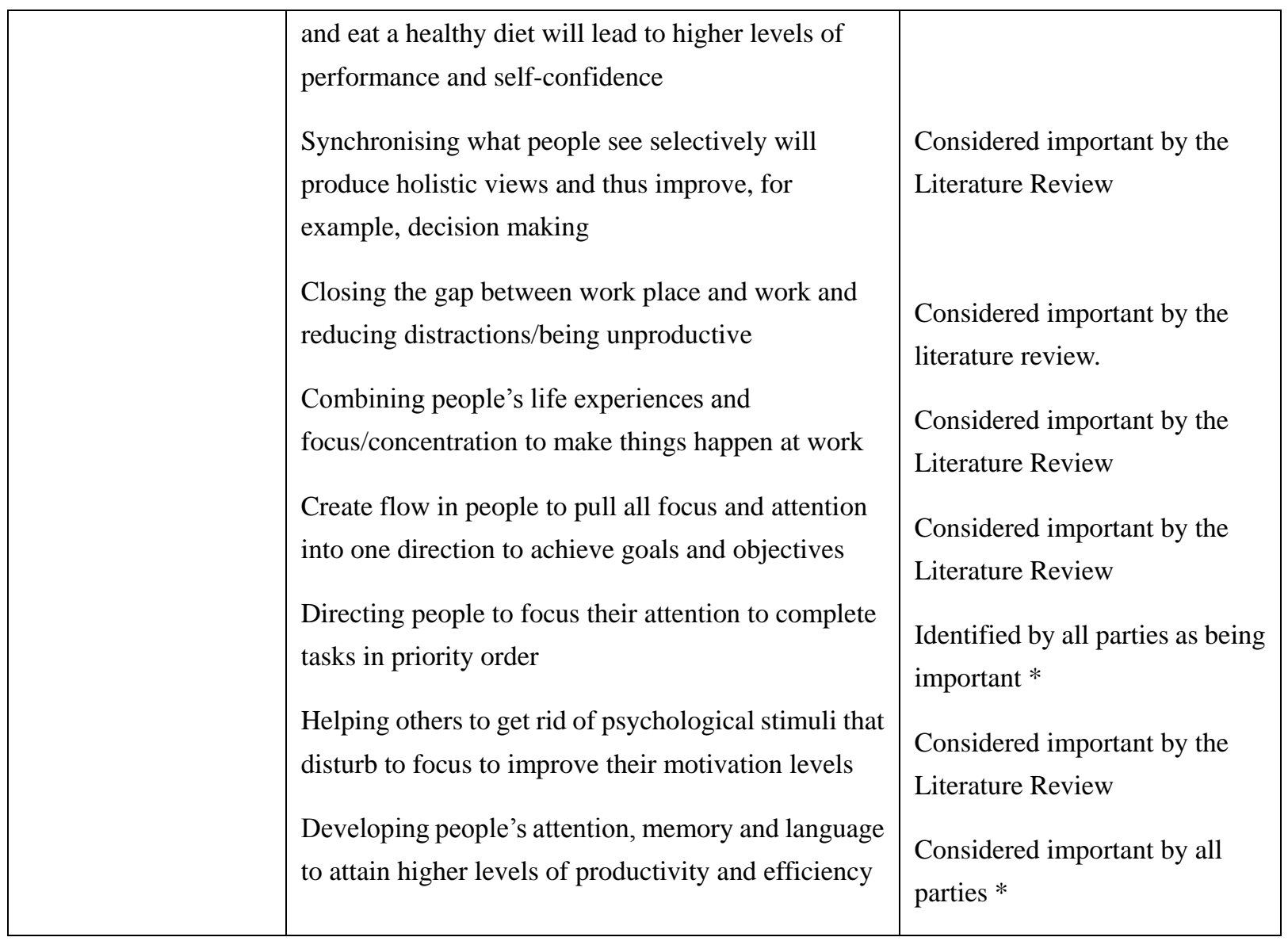

*Literature review and face to face interviews

\section{Discussion}

The phenomena of focus and attention have not been formally recognized until the late $19^{\text {th }}$ century. It appears that the ability to focus on what really matters at work, for example, is becoming increasingly important to managers. This is due to the rising levels of performance expectations set by Senior Management such as achieving more in less time, with fewer resources and to higher quality standards. The available literature on focus and attention is limited which explains why this concept is not well understood, for example, in the area of general management.

People at work get distracted quite easily. Managers need to understand this as something that Brown and Fenske refer to as focus reinvestment. Managers can help their people to improve levels of focus and attention. They need to facilitate behaviours in their people that make people comfortable to stop their focus and then re-focus their attention towards new critical details. This can be achieved by focusing attention on minor distractions such as sounds, colours and textures. It appears that this helps to tone down levels of nervousness or fear or any other brain-competing performance improvement as people will concentrate their attention on what is most important to achieve success.

This research tries to close this gap by recommending a number of practical approaches to improve the focus and attention levels of people at work (Fig.5). If adopted, it will be possible, 
for example, for managers to improve the performance levels of their team (s). The results from the literature review and face to face interviews indicate that people who focus their attention on what they do, are more likely to be successful at whatever they set their minds on. This needs to be driven by managers who must also improve their focus and attention levels first so that whole team performances can be optimized. When focus and attention levels are raised, it is possible to experience something referred to as 'flow'. This state of flow or sense of free-flowing actions is needed when attention levels need to be very high and undivided such as during car racing.

It is possible to create this state of flow for application in work situations that require people's full attention to perform at their best. It is a necessary condition that people see the value of flow and what effects this has on people's behavior, attitude, intonation of voice and body language. This increases their motivation levels to try something different, for example, to just doing their work in the usual way. The real world people live in requires that people have both divide and focused attention to deal with and manage the intricacies of, for example, priority work packages. People need to be able to work within their abilities.

It will also be necessary for people not just to focus on one thing and shout out anything else. This could lead to duplication of effort and lead to counterproductive performances. When applied appropriately and in line with, for example, prevailing requirements, managers can develop higher motivation levels within their team members. People's self-esteem and self-belief will increase. Combining experience and focus is a very powerful combination that can, ultimately, lead to new and extraordinary ecstatic states within teams and individuals.

Focus, Concentration and

Flow

Increased Performance

Attention

\begin{tabular}{|c|c|c|}
\hline Single Stimulus & Free-Flowing Action & Emotional Stimulation \\
\hline Body Language & & \\
\hline $\begin{array}{l}\text { Specific Characteristics } \\
\text { Visual Selections }\end{array}$ & Appropriate Responses & Motivation \\
\hline $\begin{array}{l}\text { Motor Skill Performance } \\
\text { Divided and Focused Attention }\end{array}$ & Self-Contained World & Positive Self-Beliefs \\
\hline Attention Blindness & Act within Abilities & Experience and Focus \\
\hline Broad, Narrow, Internal and & & \\
\hline External Focus & Ecstatic State & \\
\hline Focus Re-investment & & \\
\hline Masking Distractions & & \\
\hline
\end{tabular}

Fig. 5. The Relationship between Focus/Concentration, Attention, Flow and Increased Performance (Fisher and Santana Gonzalez, 2015)

\section{Conclusions}

Performance improvements at work are possible with relatively minimum effort. Managers need to learn the new skill of 'focus and attention' to create the phenomenon known as 'flow' within themselves first. The next step will be to create working environments that are conducive to the learning and adoption of new skills. Based on their own experiences and 
working knowledge of focus and attention and flow, managers need to sell their staff the benefits of becoming more focused in everything they do. Increased performance can be achieved by people being more emotionally stimulated, motivated and holding higher levels of positive self-beliefs. For this to work well and effectively, managers need to lead by example.

They need to enrich learning with personal practical experiences, both positive and negative, to provide some appropriate balance. Provided the right conditions have been created, increased performance levels can be expected. Managers must not get side-tracked if things do not go according to plan. They need to have a back-up plan with positive re-enforcements. It appears that acquiring a new skill requires some changes in people's attitudes and associated behaviours (Fisher and Santana Gonzalez, 2013). Managers need to influence their staff in such a way that this unfreezes the values and beliefs people hold. This will help people to develop this new skill and increase their performance levels at work.

It is a (long term) investment so giving up at an early stage is not considered to be an option if managers wish to succeed. They need to approach this change in such a way that people believe that it is their idea. This has the potential to gain people's commitments and not just compliance (short term). Compliance is short lived and may be a 'one off' fix whereas commitment is long lived. It is possible to review 'before' and 'after' performance levels (Key Performance Indicators or KPIs).

Collected data, either quantitative or qualitative, can be measured by analysing and evaluating the outputs. This allows for:

- Corrective action to be taken

- Fine-tuning of the process

- Conclusive and tangible evidence to prove the value and benefits of strengthening people's focus, attention and flow levels at work

Flow is made up of a number of necessary or contingent components, as discussed, such as mental and emotional fitness, creating an ecstatic state and masking distractions (Fig.6). It is suggested that any combination of these (at least two) will enable 'flow' to develop.

This research was limited to insights and topic experiences from a large number of students from one University in Cuba. It would have been beneficial to engage with more students from Universities from other countries to produce more universal outputs. It is confirmed that the research questions from Section 1.3 have been answered. 


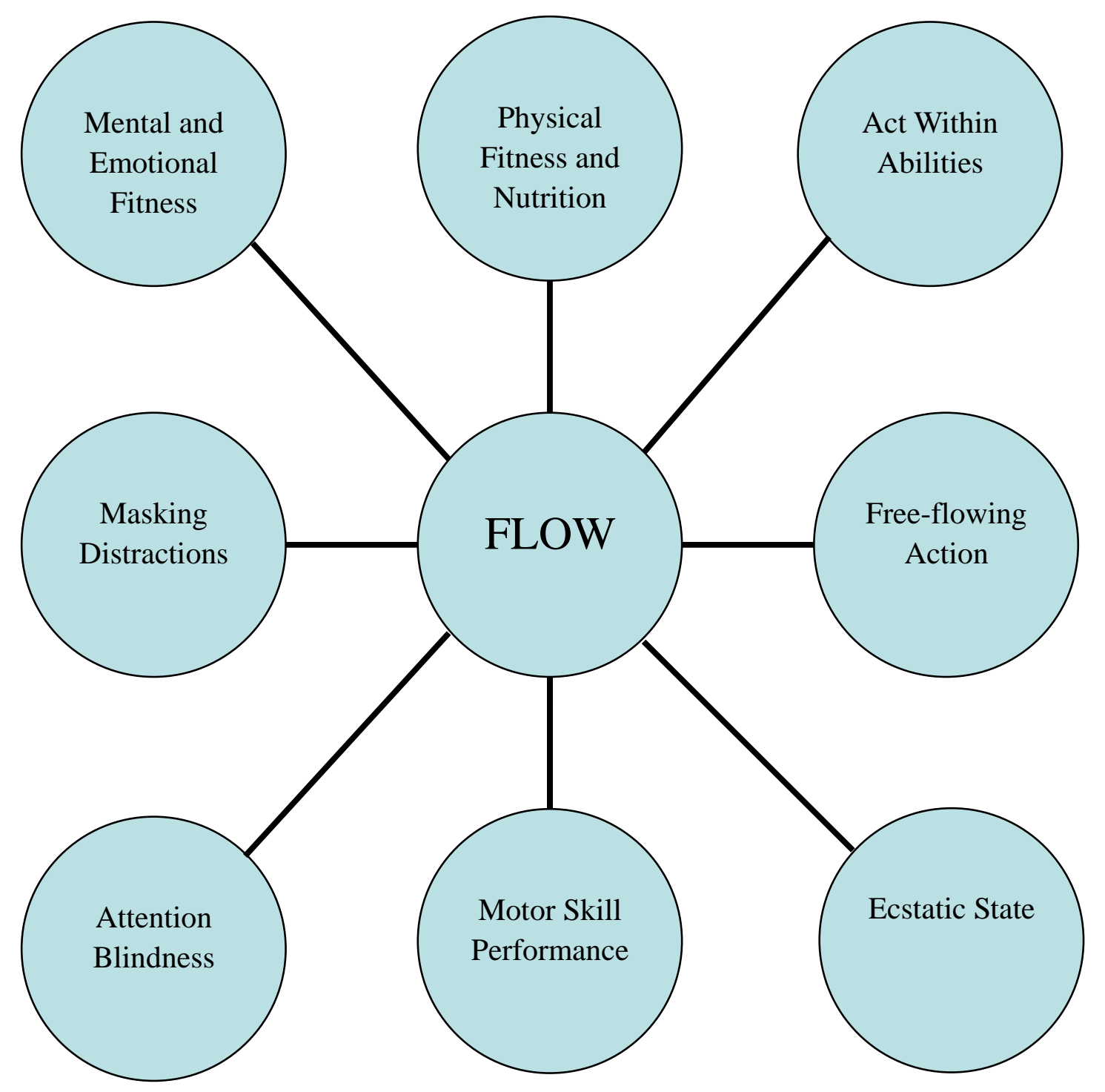

Fig. 6. Components of Flow (Fisher and Santana Gonzalez, 2016)

\section{Acknowledgements}

The corresponding author wishes to thank the Universidad de Oriente in Santiago de Cuba for providing access to interview students from the Faculty of Psychology/Social Psychology outside of formal teaching hours to assist with the completion of this research.

\section{References}

Beilock, S. (2010). Choke-The Secret of Performing under Pressure, Constable, UK

Brown, J., \& Fenske, M. (2010). The Winner's Brain-8 Strategies Great Minds Use to Achieve Success, Da Capo Press Life Long

Cairo, J. (1998). Motivation and Goal-Setting: How to Set and Achieve Goals and Inspire Others, Second Edition, Casper Press 
Cranfield, J.; Hansen, M. C., \& Hewitt, C. (2013). The Power of Focus, Vermilion

Csikszentmihalyi, M. (1997). Finding Flow-The Psychology of Engagement with Everyday Life, Basic Books

Csikszentmihalyi, M. (1991). Flow-The Psychology of Optimal Experience, New York: Harper Collins

Fisher, E.J.P. and Santana Gonzalez, Y. (2013).The ABC Manager-How to Manage People More Effectively in Today's Challenging and Demanding Work Environments, Engineering Management Research, Vol.2 (1), Canadian Center of Science and Education, doi:10.5539/emr.v2n1p67

Focus, released 27 February 2015, Warner Bros. Pictures, http://en.wikipedia.org/wiki/Focus_(2015_film)

Goleman, D. (1998). Working with Emotional Intelligence, London: Bloomsbury

Gorman, T. (2007). Motivation, Edina, MN: Adams Business

Hood, B.; Gilchrist, I. and Robertson, I. (2014). Source: http://www.redbull.co.uk/focus, accessed on 3 August 2014

Internet:

Definition of Focus:

a.) http://www.wordhippo.com/what-is-the-meaning-of-the-word-focus.html, accessed on 3 August 2014

b.) http://www.thefreedictionary.com/focus, accessed on 3 August 2014

c.) http://www.redbull.co.uk/focus, accessed on 3 August 2014

James, W. (1890, 1950). The principles of psychology, Vol. 1, New York: Holt, Reprinted in 1950 by Dover Press, New York

Johnson, A. and Proctor, R.W. (2004). Attention: Theory and Practice, Sage Publications http://dx.doi.org/10.4135/9781483328768

Mackworth, J. F. (1970). Vigilance and attention, Penguin Books Ltd., United Kingdom

Magill, R. A. (2011). Motor Learning and Control, Ninth Edition, McGraw-Hill International Edition

Nideffer, R. M. (1995). Focus for success, San Diego: Enhanced Performance Services

Pillsbury, W. B. (1908). Attention, Reprinted in 1973 by Arno Press, New York

Schmidt, R. A., \& Wrisberg, C. A. (2000). Motor Learning and Performance, Second Edition, Human Kinetics

Ribot, T. (1890). The psychology of attention, Chicago: Open Court Press 


\section{Macrothink}

Business and Economic Research

ISSN 2162-4860 2016, Vol. 6, No. 1

Sasson, R. (2012). How to Focus your Mind-Improve your Concentration, PDF e-Book

Simons, D. J., \& Chabris, C. F. (1999). Gorillas in our midst: sustained in attentional blindness for dynamic events, Dept. Of Psychology, Harvard University, 33 Kirkland Street, Cambridge, MA 02138, USA

Tsaousides, T. (2015). Brain blocks: Overcoming the 7 Hidden Barriers to Success, New York: Penguin Random House

Yerks, R. M., \& Dodson, J. D. (1908). The relation of strength of stimulus to rapidity of habit-formation, Journal of comparative Neurology and Psychology, 18, 459-482. http://dx.doi.org/10.1002/cne.920180503

\section{Copyright Disclaimer}

Copyright for this article is retained by the author(s), with first publication rights granted to the journal.

This is an open-access article distributed under the terms and conditions of the Creative license (http://creativecommons.org/licenses/by/3.0/).1 